\title{
User involvement in the electromedical device development process of small companies
}

\author{
Carina Campese ${ }^{a}$ (D), Ana Paula Siqueira Silva de Almeida ${ }^{b}$ (D), Janaina Mascarenhas ${ }^{a *}$ (D) \\ a Departamento de Engenharia de Produccão, Universidade de São Paulo - USP, São Carlos, SP, Brasil \\ ${ }^{b}$ Departamento de Engenharia de Produccão, Universidade Federal de Itajubá - UNIFEI, Itajubá, MG, Brasil \\ e-mails: carina.c@usp.br; apssalmeida@unifei.edu.br; jana.mascarenhas@usp.br
}

\begin{abstract}
To ensure good usability of electromedical devices (EMD) and to mitigate problems of misuse, IEC 60601-1-6 was implemented in Brazil, which refers to the usability engineering process of IEC 62366. With the mandatory application of such standards, the importance of user involvement throughout product development becomes even more evident, a practice that is already considerably stressed in the literature. In this context, this paper aims to investigate how the user is involved in the development of EMD, in light of the IEC 60601-1-6 requirements, mainly to understand if the obligation of the standard promotes user involvement. By means of case studies, it has been identified that the companies involve the user in a few phases of the product development. Further, although there are few methods applied for such, it is concluded that the standard of usability is being followed, but is not being applied effectively. It is necessary to develop a model that guides and encourages the companies of EMD to involve the user in the development of their products.
\end{abstract}

Keywords: usability standard, medical devices, product development process, user-centred design, participatory design.

\section{Introduction}

Usability is the ability of a system to satisfy user needs, and it is related to how well a user can utilize the functionality of a system (Nielsen, 1993). Product specifications interfere directly on the manner users interact with the product (determining and even limiting the actions of the product use), therefore, it is desirable to analyze and take into consideration the usability of the product since the early stages of the design process (Chang et al., 2017). To achieve usability, various visual interaction techniques can be applied to enlighten user needs and requirements, such as virtual or physical simulations (Zitkus et al., 2018). In addition to the research of physical abilities, usability studies evaluate human cognition, as can be seeing on the studies of Clark et al. (Clark et al., 2017).

The lack of usability in an electromedical device (EMD) can induce errors and or lead to dangerous situations due involving the misuse of these products. Medical device utilization errors are a common cause of patient injuries and even patient deaths (Zhang et al., 2003). The results of a 2013 survey suggest that one in four medical errors during surgeries are consequences of problems of technology or of the equipment itself (Rezende et al., 2015). These errors can occur due to inability of professionals to properly use the equipment, equipment defects, or even bad design decisions.
To ensure the pursuance of usability in medical devices projects, the International Organization for Standardization (ISO) has established technical standards and procedural standards on this subject. Owing to the expansion of this market in Brazil, which in 2018 occupied the fifth place in the most attractive market in the region of the Americas for medical devices' marketing (Associação Brasileira da Indústria de Artigos e Equipamentos Médicos, Odontológicos, Hospitalares e de Laboratórios, 2018), the Brazilian Association of Technical Standards (ABNT), which is the representative of ISO in Brazil, also established standards related to electromedical equipment (Pereira, 2014). Some of these standards are mandatory requirements for the Brazilian registration of the manufactured product conferred by the National Health Surveillance Agency (ANVISA), and others are only recommendations.

The international standard IEC 62366 (Medical Devices - Application of usability engineering to medical devices) describes implementation of a process to analyze, specify, design, verify, and validate the device usability. This standard is intended to minimize the risks of medical errors caused by errors of use. Owing to its importance, a Brazilian national version (ABNT NBR IEC 62366) was established. This standard is cited in the ABNT NBR IEC 
60601-1-6 series (referring to usability in electromedical equipment), and its application became mandatory since December 2015 (Brasil, 2015).

It is presumed that the introduction of these standards in the EMD industry has, in some way, altered the development process of such products, as it requires the introduction of practices to promote usability. There are some Product Development (PD) process models specifically for medical devices (e.g. Aitchison et al., 2009; Alexander \& Clarkson, 2002; Das \& Almonor, 2000; Panescu, 2009; Pietzsch et al., 2009; Shah et al., 2009), but there are no data regarding the extent or manner in which industries are implementing these models. Nevertheless, these models have an intensive focus on validation and verification of the product's functionality rather than on usability issues. Accordingly, even when a company partially adopts these models, they would still be required to adapt their development processes to meet the usability standards. It is worth to do such adaptations, recent studies (Guo et al., 2017) have reported how intense and relevant can be the users contributions for product design. Indeed the role of users at the design process is increasingly seen as strategic, therefore it would be interesting for the electromedical industry to take advantage of this best practice.

The PD models imply that users must be involved, which is reiterated by the usability standard (Figure 1). The aim of this article is to present the results of an investigation regarding how user involvement is being conducted to comply with the mandatory usability standard ABNT NBR IEC 60601-1-6 (Associação Brasileira de Normas Técnicas, 2013). The investigation was performed in the context of small Brazilian companies. This research also intends to contribute to the following question: does the mandatory nature of the usability standard promote user involvement in the development of EMD? It is expected that the practice of user involvement to be effective for EMD, and that the standard foster the positives effects that literature propose about user involvement in products development.

\section{Electromedical devices development}

First of all, it is important to define that medical devices are "any instrument, apparatus, implement, machine, appliance, implant, reagent for in vitro use, software, material or other similar or related article, intended by the manufacturer to be used, alone or in combination, for human beings, for one or more of the specific medical purpose(s) of (World Health Organization, 2020):

- Diagnosis, prevention, monitoring, treatment or alleviation of disease;

- Diagnosis, monitoring, treatment, alleviation of or compensation for an injury;

- Investigation, replacement, modification, or support of the anatomy or of a physiological process;

- Supporting or sustaining life;

- Control of conception;

- Disinfection of medical devices;

- Providing information by means of in vitro examination of specimens derived from the human body".

In addition, an electromedical device is an electrical equipment that has an applied part that transfers energy to or from the patient, or detects such energy transfer to or from the patient. This equipment's energy can be used for the purposes of diagnosis, treatment or patient monitoring, or compensation or relief for illness, injury or disability (Associação Brasileira de Normas Técnicas, 2013).

In this work we present an analysis of seven product development models (the more often cited in the literature), specific to medical devices (Aitchison et al., 2009; Alexander \& Clarkson, 2002; Das \& Almonor, 2000; Martin et al., 2010; Panescu, 2009; Pietzsch et al., 2009; Shah et al., 2009). These process models present best practices and specific methods that can be applied throughout the

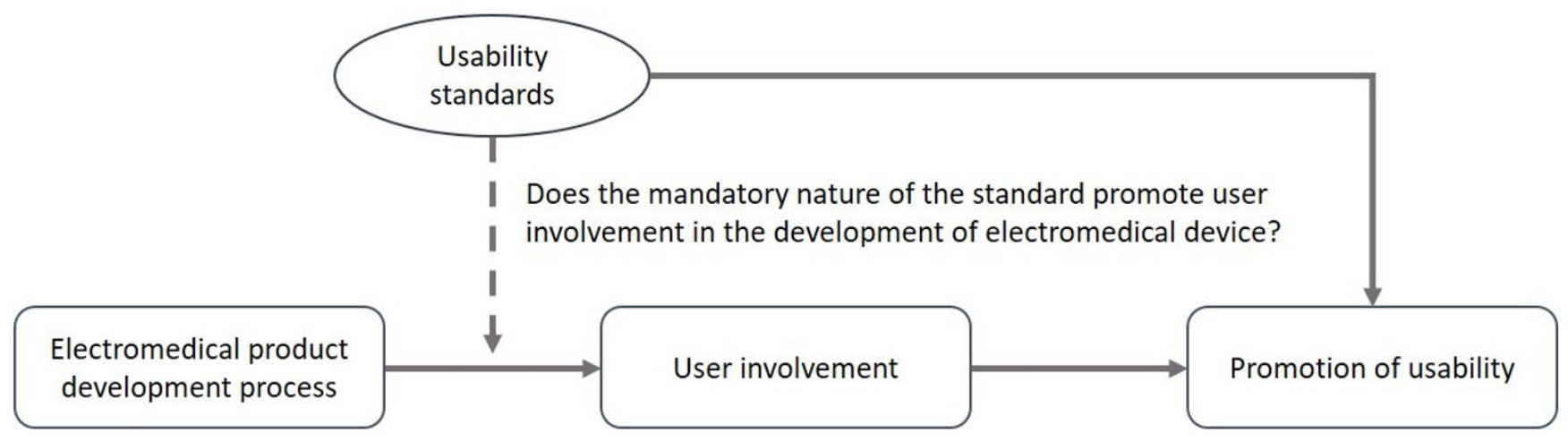

Figure 1. Research question related to the themes studied. 
development of EMD. Process models generally have a division of their activities, either in phases (Panescu, 2009; Pietzsch et al., 2009), steps (Alexander \& Clarkson, 2002; Das \& Almonor, 2000), or even stages (e.g. Aitchison et al., 2009; Martin et al., 2010; Shah et al., 2009). Regardless of nomenclature, what matters indeed are the activities. Thus, companies can use this reference to adapt or improve their own development processes.

These models have different focuses and coverage; one of them was formulated based on good practices proposed by the authors and also on regulatory standards, although the authors do not mention which standards were consulted (Pietzsch et al., 2009). Other has a clear focus on validation and verification (Alexander \& Clarkson, 2002), and other is focused on the insertion of the user in his/her model, with specifications of steps for development of new products in the market and steps for improvement of existing products (Shah et al., 2009).

In terms of scope, it is common for authors to divide the process into three macro phases: pre-development, development, and post-development. In the pre-development macro-phase it is important for companies to engage with the user to check new opportunities, and to identify barriers, and inherent risks. In the second macro-phase it is also important to involve users to identify their needs (Alexander \& Clarkson, 2002; Pietzsch et al., 2009; Shah et al., 2009), which will serve as a basis for generating concepts (Aitchison et al., 2009; Alexander \& Clarkson, 2002). Later, they can be involved to test the concepts (validations and verifications) (Shah et al., 2009). The post-development is marked by a surveillance of the quality of the product released (Panescu, 2009), through feedback from users
(Aitchison et al., 2009; Shah et al., 2009). This feedback should be evaluated continuously (Aitchison et al., 2009), so that improvements in product design (Aitchison et al., 2009; Pietzsch et al., 2009) and in the manufacturing process (Pietzsch et al., 2009) can be made. It is noted that this last phase of the models is of extreme importance to the project team, and that user involvement is essential. Despite this, only half of the models have post-development phases.

All the phases and stages of the analyzed models are shown in Figure 2. Looking at the models, some gaps can be noticed when they are compared with others (gray areas). This indicates that, although the models have a general logic of activities performed, not all of them have the same information. In addition, not all models are iterative. Only in three models is iteration precisely and clearly mentioned (Aitchison et al., 2009; Pietzsch et al., 2009; Shah et al., 2009).

It is also noted that most models mention verification and validation. However, it can be stated that the focus of these verifications and validations is in the engineering area, e.g. feasibility tests (Pietzsch et al., 2009), software operating tests (Panescu, 2009), risk analysis, and FMEA (Aitchison et al., 2009). Only in two models the usability test is mentioned (Martin et al., 2010; Shah et al., 2009).

Of the studies analyzed, some specify which users the project team should contact, as follows:

- Health professionals: doctors (Das \& Almonor, 2000; Martin et al., 2010; Pietzsch et al., 2009; Shah et al., 2009), nurses (Martin et al., 2010; Pietzsch et al., 2009; Shah et al., 2009), physiotherapists (Martin et al., 2010);

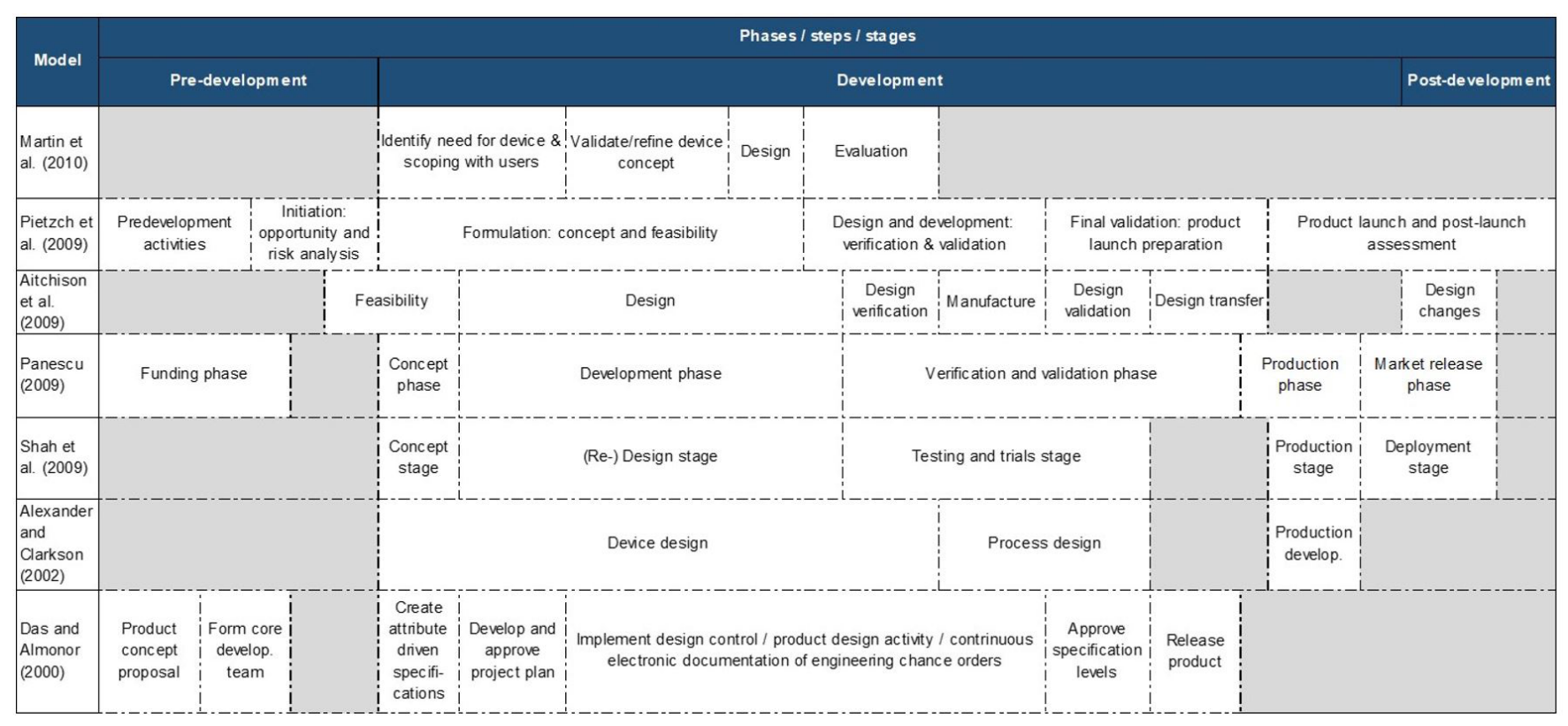

Figure 2. Phases, steps and stages of the EMD development processes. 
- Patients with disabilities or with special needs (Shah et al., 2009);

- Elderly patients (Shah et al., 2009);

- Patients in general (Das \& Almonor, 2000; Martin et al., 2010; Pietzsch et al., 2009; Shah et al., 2009);

- Caregivers of patients (Martin et al., 2010; Shah et al., 2009);

- Technicians (Pietzsch et al., 2009);

- Professionals who have contact with the product: people who do their maintenance, cleaning, transportation, training, etc. (Martin et al., 2010);

- Patients' relatives (Martin et al., 2010).

Users can be involved during the product development in different levels. Products can be designed on behalf of the user, based on his/her behavior, preferences and needs (such user involvement approach is called "design for"). Another way to involve users is to "design with" the users, in other words, users can react to the different proposed design solutions in this approach. In a higher level of involvement, users participate in the design process as part of the design team (approach called "design by") (Eason, 1992; Macaulay, 2012).

\subsection{Usability in the electromedical devices}

Usability is the ability of a system to satisfy user needs (Nielsen, 1993), and it is traditionally associated with the following aspects: learning ability (it should be easy to learn to use the system), memorization (the system must have a low error rate, if any) (Nielsen, 1993), efficiency (the use of the system must be efficient if it achieves high productivity), satisfaction (the system should be pleasant to use so that users are satisfied) (International Organization for Standardization, 1998; Nielsen, 1993) related to comfort (Nielsen, 1993), effectiveness (accuracy and integrity with which users reach their objectives, accessing the correct information or generating the expected result), and context of use (physical and social environment in which the product is used) (ISO 9241-11, 1998). Given the latter aspect, it is evident that usability is also related to the environment in which the user performs his/her activities, and not only to the way in which he/she performs them.

In order to guarantee usability of medical devices, ISO has established technical norms and standards of procedure on this subject. In Brazil, the standard regarding usability of such devices (Associação Brasileira de Normas Técnicas, 2013) became mandatory in 2015 (Brasil, 2015). This standard refers to usability as a process, referring to ABNT NBR IEC 62366 (Associação Brasileira de Normas Técnicas, 2016) (which refers to health products), that should be applied in parallel to the Product Development Process (PDP). The usability engineering process proposed in the standard contains six steps, as can be seen in Figure 3: user research, conceptual design, requirements and criteria development, design and specification, and evaluation and deployment. At each step, some specific activities are required, which must be registered by the company.

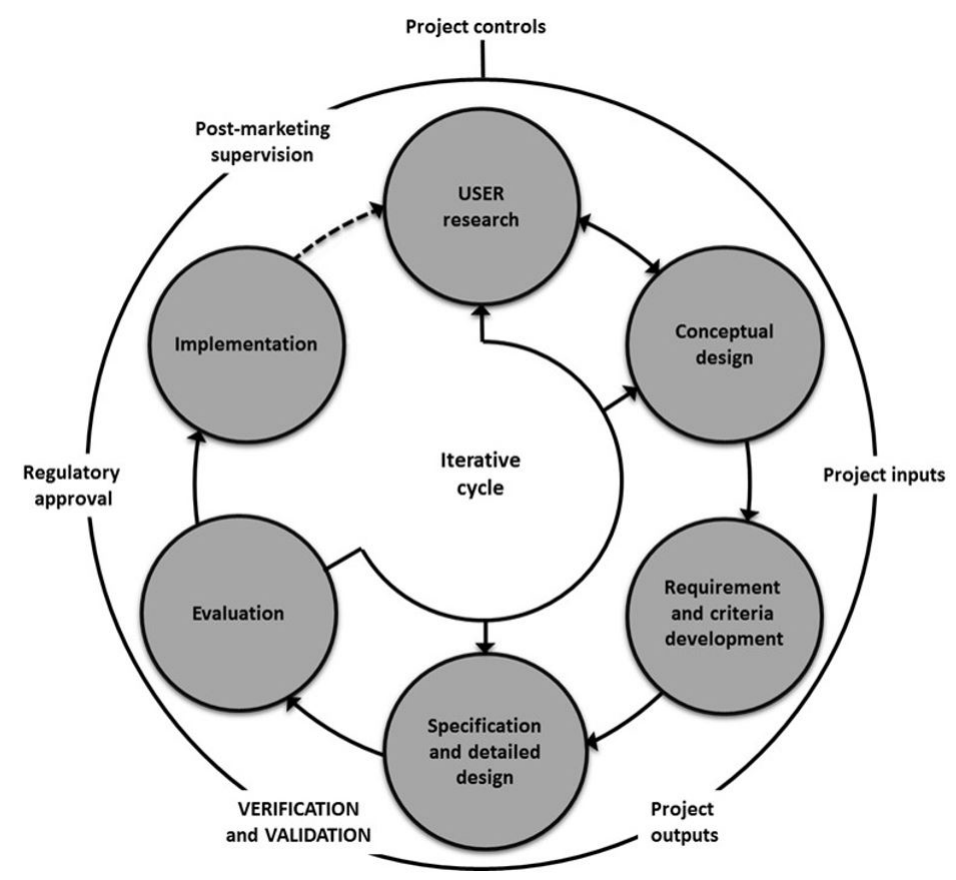

Figure 3. Engineering usability process from IEC 62366. Font: Associação Brasileira de Normas Técnicas (2016). 
The standard emphasizes that user involvement must be performed with "representative" users; however, there is no definition for this term, which may generate doubts at the time of its application.

\section{Methodology}

Five case studies were conducted in small companies in the medical sector. The methodology of the case study used was proposed by Yin (Yin, 2011). The method is appropriate for analyzing contemporary situations within a real context. For the selection of the companies, three criteria were defined: (I) to have at least two projects in progress per year, (II) to execute both new projects and product improvement projects, and (III) to have as a requirement for product certification the standard ABNT NBR IEC 60601-1-6. Professionals interviewed should be from the project engineering team and / or the quality team of the companies. As presented in Table 1, the companies interviewed develop products in the areas of ophthalmology, gynecology, otolaryngology, neonatology, general medicine, aesthetics and odontology. Eleven professionals were face to face interviewed.

Medical companies are classified with a risk class (intrinsic risk that the product presents to the health of the patient, operator, or third party), which varies from I (low risk) to IV (maximum risk) (Brasil, 2001). Only one of the selected companies develops products that fall in risk class I and II (low and medium risk); the other companies develop products that fall in class III (high risk) for both diagnostic and surgical purposes.

The exploratory case studies followed the protocol described in Table 2. Identification data of the phases and activities carried out in the product development process of the companies, and how user integration in this process is performed were compared with the data of stages and user involvement that are required by the current standard.

\section{Results and discussion}

Owing to the obligatory nature of the standard, all the analyzed companies follow ABNT NBR IEC 60601-1-6 (the usability standard), which means, in theory, that they all involve the user during the PDP.

The results are presented below in three sections. First, it is reported how the importance of user involvement in the development of products in companies is understood. It is then presented when users are involved in the product development process, both in new projects and in projects for improvements than has already been released. Finally, the way in which this occurs is presented (the methods that are applied to involve the user in this process).

Table 1. Description of the companies.

\begin{tabular}{|c|c|c|c|c|c|}
\hline Company & Founded in & Product line & $\begin{array}{c}\text { Number of employees } \\
\text { of the P\&D team }\end{array}$ & Number of interviewees & Classification \\
\hline A & 1999 & $\begin{array}{c}\text { Ophthalmology, } \\
\text { gynecology and } \\
\text { otolaryngology }\end{array}$ & 6 & 1 & III (highest risk) \\
\hline B & 1992 & Ophthalmology & 8 & 3 & $\begin{array}{c}\text { I and II (low and } \\
\text { moderate risk) }\end{array}$ \\
\hline C & 1956 & Neonatology & 4 & 1 & III (highest risk) \\
\hline D & 1998 & $\begin{array}{c}\text { Odontology, general } \\
\text { medical, aesthetic }\end{array}$ & 9 & 3 & III (highest risk) \\
\hline E & 2015 & $\begin{array}{c}\text { General medical, } \\
\text { odontology and aesthetic }\end{array}$ & 7 & III (highest risk) \\
\hline
\end{tabular}

Table 2. Research protocol for case study.

\begin{tabular}{|l|l|}
\hline Master research question & \multicolumn{1}{|c|}{$\begin{array}{c}\text { How is the user involved in the development phases of electromedical devices to increase their } \\
\text { usability? }\end{array}$} \\
\hline Scan theme & PDP of the companies of electromedical products \\
\hline Schedule & Interviews conducted between October 2016 and July 2017 \\
\hline \multirow{2}{*}{ Validity of buildings } & $\begin{array}{l}\text { Comparison between practice and theory, based on literature review (product development processes and } \\
\text { standar models) }\end{array}$ \\
\hline \multirow{2}{*}{ Techniques used } & Interviews with engineers for data collection \\
\cline { 2 - 2 } & Company documentation review \\
\hline \multirow{3}{*}{$\begin{array}{l}\text { Issues underlying the } \\
\text { exploratory case study }\end{array}$} & What are the phases and activities carried out in the company's product development process? \\
\cline { 2 - 2 } & How is the user involved in the product development process? \\
\cline { 2 - 2 } & What are the main methods used? \\
\cline { 2 - 2 } & What are the main standards followed? \\
\hline
\end{tabular}




\subsection{Understanding the importance of the user in product development}

As pointed out by the usability process (Figure 3), the user should be involved in product development, especially in the user research and design, detailed design $\&$ specification, and evaluation steps. Companies recognize the benefits of engaging the user in product development, but not uniformly.

Some mention that contact between the project team and the user is beneficial. The main benefit pointed out by all companies is that, with the involvement of the user, the company identifies / prioritizes products to develop, and therefore, spends less time and resources. It was also noticed by Company $\mathrm{B}$ that it is possible to obtain user feedback when a product is already in the market, which allows the company to generate improvements for future projects. Company D also acknowledges these benefits; however, it stresses that it is essential to contact the right user to get adequate feedback. According to the interviewee of company $\mathrm{D}$, users are frequently approached during events and trade shows. At these events, company representatives present and explain new products new functionalities. It would be a waste of time if the company had to inform clients about the impossibility of developing other functionalities owing to regulatory issues, instead of receiving useful feedback.

Company $\mathrm{C}$ has a barrier to user engagement. The company sees no benefit in involving the users throughout the development of medical products. According to one of the interviewees, there is a big conflict between what the user wants and the standards that need to be followed. In this way, the company only listens to the user before starting the project, filters the requirements by the standards, and develops the product.

Thus, it is observed that the importance of user involvement is perceived by all companies as a way to identify users' needs and to validate the product. However, the importance of contact with the user to other stages of product development is limited, especially in the steps that trace the users' profiles and prioritize their requirements, as can be seen in Figure 4. In addition to recognizing this importance, it is necessary to check when and how this involvement with the user happens in practice.

\subsection{Phases of product development with user involvement}

Among the companies analyzed, only two (C and $\mathrm{D})$ adopt a reference model. Company $\mathrm{B}$, at the time of the interviews, stated that it was undergoing a process of formalization, documenting the steps that are followed based on other standards steps. Companies C and D, when

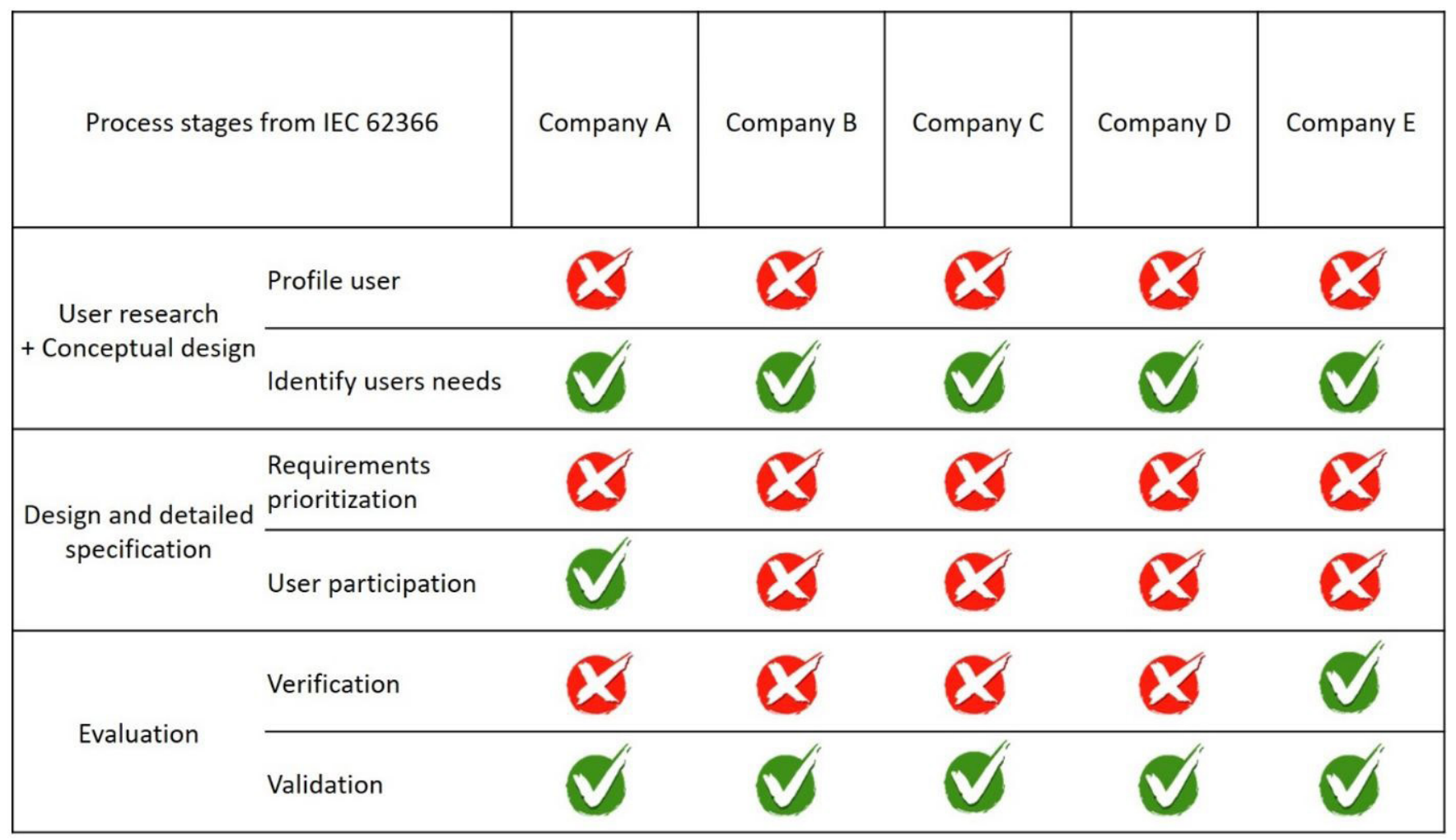

Figure 4. Understanding the importance of user involvement throughout product development, from the perspective of companies. 
indicating the phases followed for product development, indicated phases and sequences similar to those of the usability engineering process (see Figure 3 ). In this way, as the companies analyzed do not follow the same model of product development, the identification and analysis of the occurrences of the user involvement in this work were done by establishing a reference with the process of usability of the ABNT NBR IEC 62366 standard (which refers to health products), that should be applied in parallel to the PDP.

Despite the importance of user involvement in many stages of product development (Associação Brasileira de Normas Técnicas, 2016; Macaulay, 2012), none of the companies performed activities with the users to trace their profile. Moreover, to survey user needs, only two companies (A and B) demonstrated evidence of involving users.

During conceptual design, the involvement of the user would also be possible, as the user can be part of the idea generation, being involved in the project in a greater level of interaction (Macaulay, 2012). In the companies analyzed, only company A has a system of inviting the user to participate in the generation of concepts. In this way, the user has the possibility to suggest his/her ideas of a solution to the problem (they are not always viable and are considered, but they have this freedom and opportunity). The other companies do not promote contact with the user to generate product ideas; they only use data and information from previous projects.

Throughout product development, it is necessary to plan the usability validation: to elaborate and follow a protocol of established criteria, to contact the users that will be involved, and to specify which method will be used (Associação Brasileira de Normas Técnicas, 2016). Thus, although it is not straightforward to involve the user, it is necessary to focus on user involvement to plan usability validation. Despite this, only two companies comply with this requirement ( $\mathrm{A}$ and $\mathrm{B}$ ) by preparing with company partners for future testing. The other companies do not prepare for usability validation in advance.

In the evaluation stage, it is necessary to verify and validate the usability of the product (Associação Brasileira de Normas Técnicas, 2016). It should be noted that the verification can occur during the entire development process, and that for the validation of the final version of the product, the involvement with the user is required. In practice, this does not happen uniformly in the companies analysed. None of the companies analysed performs verification of usability throughout product development, only performing it at the end of the process. One of the companies (E) claimed to check the usability of the product in the intermediate stages of the product development process, but the tests performed are related to engineering (electrical and mechanical operation of the product) rather than to usability itself. In addition, there is no user involvement in these tests. Validation is performed by all companies, but only in two of them (A and $\mathrm{B}$ ) is it performed with the user.

In this way, the user is involved in a few steps in the product development of the companies analysed, as can be seen in Figure 5, where the stages of product development with user involvement are indicated (Associação Brasileira de Normas Técnicas, 2016), and the percentage of companies that undertake such involvement for these purposes. For the user and conceptual design steps (performed together), the user is only involved to identify their needs and yet, this occurs in a minority of companies. As the requirements step requires a greater focus on the user, not specifically their involvement, this step was disregarded in this analysis. In the detailed design and specification stage,
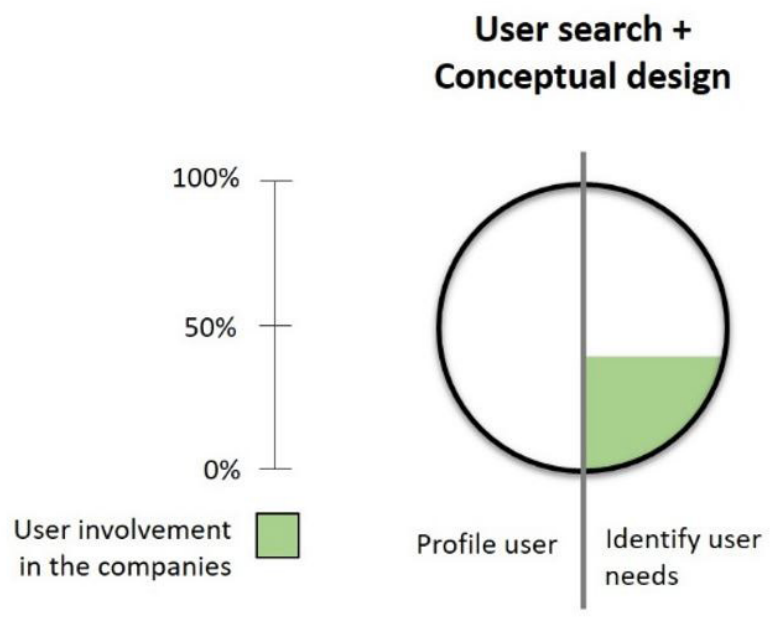

\section{Design and detailed specification}

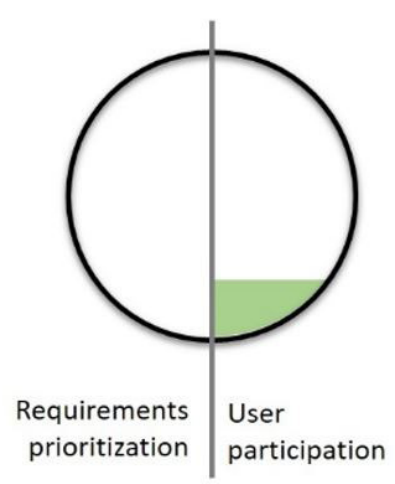

\section{Evaluation}

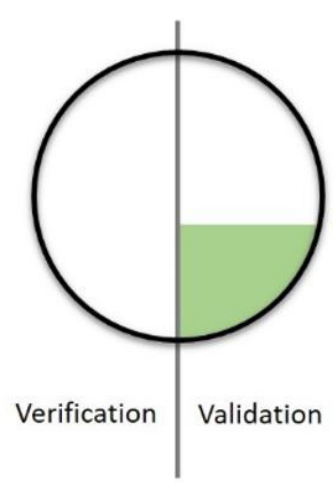

Figure 5. Stages of product development with user involvement. 
no company prioritizes the requirements, and all focus very little on user involvement, and for generating ideas; only one company has contact with the user. Only part of the evaluation is performed with the user (validation), which in turn occurs in a minority of companies.

\subsection{Methods applied to involve the user in product development}

The methods that can be applied throughout the usability process are task analysis, usability testing, observation, scenarios, prototyping, brainstorming, interviews, contextual inquiry, heuristic evaluation, and questionnaires (Associação Brasileira de Normas Técnicas, 2016). In addition, it is believed that other methods could also be applied (e.g., persona, empathy map, and user stories). Through the interviews, it was possible to identify which methods companies apply to involve the user in the development of products.

Companies $\mathrm{A}, \mathrm{B}$, and $\mathrm{E}$ engage the user actively to identify their needs through informal interviews, that is, no pre-established protocol or questionnaire is followed. In addition, the information collected is not documented. The users that are interviewed are medical partners of the companies and also doctors approached at national and international fairs and congresses. In addition, in these three companies, the involvement is carried out in a passive way through market research (applied by the commercial area of the companies) to identify feedback regarding the products already launched and possible improvements that can be made.

Companies $\mathrm{C}$ and $\mathrm{D}$ collect user needs in a more indirect way. For company $\mathrm{C}$, the market's needs are collected by research in governmental and non-governmental bids, as well as a survey of competing products. Only after the new project has been established are informal interviews conducted with professionals in the area to understand their needs. Company D does not carry out this initial involvement with the user: the product development team selects a project through the analysis of its market research (carried out by the company's commercial area).

All the companies analyzed make improvements in their products after a certain period following release of the product into the market. The design of these products then goes through an improvement process that follows the steps of the standard again. Companies A, B, and C deal with user engagement for product improvement in the same way as for a new product, that is, they conduct informal interviews to identify how the product can be improved. It also happens that the project team deploys modifications suggested by the team itself, which were archived because the product certification process was already in progress. It can be seen that the tests with the product were carried out later. On the other hand, companies D and E carry out modifications in projects based on customer service complaints and customer satisfaction surveys conducted by telemarketing (both carried out by the commercial area), that is, by interviews.

The requirements are generated based on the data from the previous step (user search) for both new projects and improvements. Although generated on this basis, none of the companies apply specific methods that help in generating product requirements that are focused on users' needs. What is accomplished is an organization and application of requirement management methods when these have already been formed by the project team (four of the five companies apply functional analysis or QFD).

The usability verification, although not performed throughout the entire product development process, is performed in all companies on $100 \%$ functional prototypes that are manufactured with the same material used for the final product. Therefore, usability is only checked when the product is practically ready, and the user involvement is not carried out.

Validation is performed in companies at different levels. Testing with prototypes is carried out in all the companies analyzed, but these tests are not applied in the same way. In the case of company $\mathrm{A}$, the tests are conducted by partner physicians at fairs or by doctors and university students at partner universities in the region, through informal interviews. In addition, a usability test, carried out in the company by the entire R\&D team and by at least one user (partner doctor), is employed. Company B also applies informal interviews with partner physicians in the company itself and / or at fairs with the use of prototypes. For companies $\mathrm{C}$ and $\mathrm{E}$, prototype testing is performed by the project team, with no users. Company D also does not involve the user in these tests, as those who apply them are consultants.

In addition, companies $\mathrm{B}$ and $\mathrm{C}$ apply the task analysis method to identify the most commonly used functions and identify product failures as specified in the standard (Associação Brasileira de Normas Técnicas, 2016). However, there is no protocol that is followed, and the results of the method are not documented.

It is concluded, then, that there are few methods applied by the companies, compared to the range of suggestions of the standard and in the literature. In addition, no useractive method is applied across all enterprises, and for some steps, no user-driven methods are applied (Figure 6). The methods used are informally applied in companies, and they search for information that could be raised in more depth together with other methods suggested by the standard (e.g., heuristic evaluation, scenarios, and 


\begin{tabular}{|c|c|c|c|c|c|c|c|}
\hline \multirow{3}{*}{\multicolumn{2}{|c|}{ Process stages from IEC 62366}} & \multicolumn{6}{|c|}{ User involvement } \\
\hline & & \multirow{2}{*}{\begin{tabular}{|c|} 
Passive \\
$\begin{array}{c}\text { Secondary } \\
\text { data }\end{array}$
\end{tabular}} & \multicolumn{5}{|c|}{ Active } \\
\hline & & & & Prototune & & Usability & \\
\hline \multirow{2}{*}{$\begin{array}{c}\text { User research } \\
\text { + Conceptual } \\
\text { design }\end{array}$} & Profile user & & & & & & \\
\hline & $\begin{array}{l}\text { Identify users } \\
\text { needs }\end{array}$ & & & & & & \\
\hline \multirow{2}{*}{$\begin{array}{l}\text { Design and } \\
\text { detailed } \\
\text { specification }\end{array}$} & $\begin{array}{l}\text { Requirements } \\
\text { prioritization }\end{array}$ & & & & & & \\
\hline & $\begin{array}{l}\text { User } \\
\text { participation }\end{array}$ & & & & & & \\
\hline \multirow{2}{*}{ Evaluation } & Verification & & & & & & \\
\hline & Validation & & & & & & \\
\hline
\end{tabular}

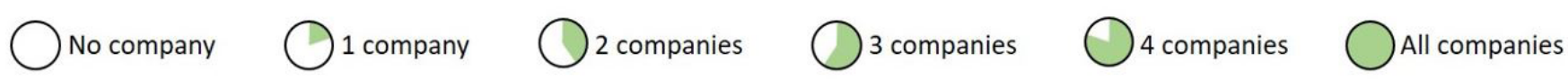

Figure 6. Applied methods with user involvement.

contextual inquiry) or even the literature (e.g., map of empathy, persona, and user stories).

\section{Conclusions}

In this paper, the user's involvement in the development of EMD in small Brazilian companies was identified. It is worth mentioning that companies of this size usually have some specific characteristics and limitations, such as resource scarcity, difficulty in accessing a high number of professionals and users for involvement. Despite this, it is of the utmost importance that such companies organize themselves to remedy these limitations, especially when it comes to achieving good usability for their products.

In principle, companies realize the importance of user involvement, as it fosters the establishment of partnerships and a post-sales communication channel, but this involvement is not yet applied throughout product development. According to companies, this happens because interviewing many users is time intensive. In addition, it is very laborious to organize all this contact, and often,
R\&D team staff are not available to do so. Moreover, a considerable amount of capital would have to be invested to apply more specific methods to the user. It is noted then that companies must understand that involving the user in certain stages of product development does not lead to a loss of resources; such involvement brings many benefits in the long run. It should be noted here that the ideal condition of user involvement should also consider the cost-effectiveness aspects of development, including that health technologies should be increasingly accessible to the population. Thus, perhaps for small companies, the user's involvement in the superficial form, financially speaking, is worthwhile; but it is extremely important that such companies start thinking about the future: less time to generate reports for certification, less problems with products, less complaints from users, more user loyalty to the brand, fewer recalls, etc.

It was possible to identify that the steps of user search and conceptual design are carried out superficially. Most companies conduct interviews with users for data collection, but the company only contacts one type of user (doctors), 
not considering other types of users (such as nurses, patients and technicians). This can significantly affect the project, as this approach does not consider the many needs and requirements of other users in product development. Thus, the company may fail to identify new market opportunities.

It was also identified that validation of the projects is not always carried out by the users themselves, but by the project team itself or even consultants. This fact can also bias the results of the conducted analyses, in addition to not complying with the requirement of the standard, which stipulates that the concept should be validated with the user.

In addition, there are few methods used that engage users. Only interview methods, prototype tests, brainstorming, and usability testing are applied; however, these methods are not applied by all companies. No specific method is applied to raise the user profile (as required by the standard), and all interviews are conducted informally. Only two companies apply a method of observation of product use to survey the most commonly used functions for the documentation that the standard requires (task analysis). Although two companies test prototypes, they are not tested by users. In addition, for the development of requirements, no evidence was found that project teams prioritize requirements based on the user.

It was observed that four of the companies analyzed (A, $\mathrm{B}, \mathrm{D}$ and $\mathrm{E}$ ) report activities only shortly before submitting the documentation for certification, and not after the end of each activity, as requested by the standard. Such a practice can compromise the quality of the reports, as they are made after the device development, and with information that may have already been forgotten by the project team.

Thus, it is concluded that the requirement of application of the standard ABNT NBR IEC 60601-1-6 minimally promotes user involvement in the development of products, but does not guarantee that this involvement is carried out in an appropriate manner, so that the users' needs are obtained and even considered during the development of EMD. This fact can influence the quality of the developed equipment, and not solve the problems of equipment misuse.

None of the companies follows the product development reference models from the literature (Figure 2). Despite this, two companies follow the usability engineering process model (Associação Brasileira de Normas Técnicas, 2016) to develop their products. It is concluded, therefore, that the models in the literature also do not promote usability of the products, as it is necessary to apply another theory to achieve a focus on usability.

It is also concluded that the standard of usability (Associação Brasileira de Normas Técnicas, 2013) is being followed, but it is not applied in an effective way. The users' involvement in the development of the companies' products is still very low, and thus, it is not possible to adequately address the needs of the user, validate the concepts with the user, and thus achieve good usability of the products.

It is therefore necessary to find a way for companies to apply, in addition to the methods focused on engineering (as suggested in the reference models), methods with a focus on the user, ensuring the involvement of the same throughout the development of products. To do this, a new model of developing EMD with a user focus is necessary. However, future studies should analyse whether such a specific process would in fact guarantee effective user involvement in product development.

It is also necessary to apply this new model with a focus on usability and user involvement in its phases, so that (I) a more specific model drives the application of focused methods to the user and (II) it specified the phases in which the user becomes involved in the development of these products. But, even more important than having a more oriented material, it is essential to have a more rigorous inspection, that is, that the enforcement agency be stricter with small companies that do not properly engage users of their products. In addition, it is important to understand how to guarantee that standards are been carefully respected to provide the aim they were meant for.

\section{Acknowledgements}

The authors thank the Higher Education Personnel Improvement Coordination (CAPES) by supporting this work.

\section{References}

Associação Brasileira da Indústria de Artigos e Equipamentos Médicos, Odontológicos, Hospitalares e de Laboratórios ABIMO. (2018). Dados do comércio exterior. Accessed November 17, 2019, from https://abimo.org.br/dados-dosetor/dados-de-comercio-exterior

Associação Brasileira de Normas Técnicas - ABNT. (2013). ABNT NBR IEC 60601-1-6. Equipamento eletromédico Parte 1-6: requisitos gerais para segurança básica e desempenho essencial - norma colateral: usabilidade. Rio de Janeiro: ABNT.

Associação Brasileira de Normas Técnicas - ABNT. (2016). ABNT NBR IEC 62366. Produtos para a saúde-Aplicação da engenharia de usabilidade a produtos para a saúde. Rio de Janeiro: ABNT.

Aitchison, G. A., Hukins, D. W. L., Parry, J. J., Shepherd, D. E. T., \& Trotman, S. G. (2009). A review of the design process for implantable orthopedic medical devices. The Open Biomedical Engineering Journal, 3(1), 21-27. http:// dx.doi.org/10.2174/1874120700903010021.

Alexander, K., \& Clarkson, P. J. (2002). A validation model for the medical devices industry. Journal of 
Engineering Design, 13(3), 197-204. http://dx.doi. org/10.1080/09544820110108890.

Brasil. (2001, Outubro 22). Resolução ANVISA RDC no 185/2001, de 22 de outubro de 2001. Regulamento Técnico que estabelece os requisitos essenciais de segurança e eficácia aplicáveis aos produtos para saúde, referidos no anexo desta Resolução. Diário Oficial [da] República Federativa do Brasil, Brasília, Poder Executivo, v. 6.

Brasil. Ministério da Saúde. Agência Nacional de Vigilância Sanitária. (2015, Setembro 25). Instrução normativa $n^{\circ} 4$, de 24 de setembro de 2015. Diário Oficial [da] República Federativa do Brasil, Brasília.

Chang, J., Jung, K., Lee, W., \& You, H. (2017). Development of a usability evaluation method using natural product-use motion. Applied Ergonomics, 60, 171-182. http://dx.doi. org/10.1016/j.apergo.2016.11.015.

Clark, L. N., Benda, N. C., Hegde, S., McGeorge, N. M., Guarrera-Schick, T. K., Hettinger, A. Z., LaVergne, D. T., Perry, S. J., Wears, R. L., Fairbanks, R. J., \& Bisantz, A. M. (2017). Usability evaluation of an emergency department information system prototype designed using cognitive systems engineering techniques. Applied Ergonomics, 60, 356-365. http://dx.doi.org/10.1016/j.apergo.2016.12.018.

Das, S. K., \& Almonor, J. B. (2000). A concurrent engineering approach for the development of medical devices. International Journal of Computer Integrated Manufacturing, 13(2), 139147. http://dx.doi.org/10.1080/095119200129984.

Eason, K. D. (1992). The development of a user-centred design process: a case study in multi-disciplinary research. Loughborough: Loughborough University of Technology.

Guo, W., Zheng, Q., An, W., \& Peng, W. (2017). User roles and contributions during the new product development process in collaborative innovation communities. Applied Ergonomics, 63, 106-114. http://dx.doi.org/10.1016/j. apergo.2017.04.013.

International Organization for Standardization - ISO. (1998). ISO 9241-11. Ergonomic requirements for office work with visual terminals (VDTs) - Part 11: guidance on usability. London: ISO.

Macaulay, L. A. (2012). Requirements Engineering. Switzerland: Springer Science \& Business Media. https:// doi.org/10.1007/978-1-4471-1005-7

Martin, J. L., Norris, B., Murphy, E., \& Crowe, J. (2010). Design for patient safety. User testing in the development of medical devices (2nd ed., p. 68). London: National Patient Satefy Agency. https://doi.org/10.1177/1064804613494681

Nielsen, J. (1993). Usability Engineering (Vol. 44). San Francisco, CA: Academic Press. https://doi. org/10.1145/1508044.1508050.

Panescu, D. (2009). Medical device development. In Engineering in Medicine and Biology Society. EMBC 2009. Annual International Conference of the IEEE (pp. 55915594). IEEE. https://doi.org/10.1109/IEMBS.2009.5333490

Pereira, A. A. (2014). Workshop sobre Certificação de Equipamentos Eletromédicos Marco Legal. ANVISA

Pietzsch, J. B., Shluzas, L. A., Paté-Cornell, M. E., Yock, P. G., \& Linehan, J. H. (2009). Stage-Gate Process for the Development of Medical Devices. Journal of Medical Devices, 3(2), 021004. http://dx.doi.org/10.1115/1.3148836.

Rezende, L. S. A., Bernardes, M., \& Mello, C. H. P. (2015). Engenharia da usabilidade aplicada ao desenvolvimento de equipamentos médicos: uma revisão sistemática. In $10^{\circ}$ Congresso Brasileiro de Gestão da Inovação e Desenvolvimento de Produtos (pp. 1-10).

Shah, S. G. S., Robinson, I., \& AlShawi, S. (2009). Developing medical device technologies from users' perspectives: A theoretical framework for involving users in the development process. International Journal of Technology Assessment in Health Care, 25(4), 514-521. http://dx.doi. org/10.1017/S0266462309990328.

World Health Organization - WHO. (2020). Medical Devices Full Definition. Retrieved in August 11, 2020, from https:// www.who.int/medical_devices/full_deffinition/en/

Yin, R. K. (2011). Qualitative Research from Start to Finish. New York: The Guilford Press. https://doi.org/10.1007/ s13398-014-0173-7.2

Zhang, J., Johnson, T. R., Patel, V. L., Paige, D. L., \& Kubose, T. (2003). Using usability heuristics to evaluate patient safety of medical devices. Journal of Biomedical Informatics, 36(1-2), 23-30. http://dx.doi.org/10.1016/ S1532-0464(03)00060-1.

Zitkus, E., Langdon, P., \& Clarkson, P. J. (2018). Gradually including potential users: A tool to counter design exclusions. Applied Ergonomics, 66, 105-120. http://dx.doi. org/10.1016/j.apergo.2017.07.015. 